\title{
Computational Study of the Formation of Phenol/p-tert-Butylphenol Co-condensed Polymers
}

\author{
Tada-Aki Yamagishi, Mitsuhiro SaKuda, Yoshiaki NaKamoto, and Shin-ichiro IshidA \\ Department of Chemistry and Chemical Engineering, Faculty of Technology, Kanazawa University,
}

Kanazawa 920, Japan

(Received February 8, 1996)

\begin{abstract}
Phenol/p-tert-butylphenol co-condensed polymers of various compositions and molecular structures were prepared by using $\mathrm{HCl}$ as a catalyst. The formation mechanism and the molecular structure were analyzed and determined by the Monte Carlo (MC) computer simulation technique. The MC simulation was run under the following assumptions : 1) the reactivity of each functional group in copolymer is independent of the chain length, 2) intramolecular reaction does not occur, and 3) dimethylene ether linkage is not formed. In the co-condensation, the rate constant of condensation reaction was about 10 times greater than that of the addition, the reactivity of the para position of phenol was about 3 times higher than that of the ortho, and the reactivity of phenol (P) was higher than that of $p$-tert-butylphenol (BP) (reactivity ratio: $\mathrm{P} / \mathrm{BP}=5 / 4$ ). From these results determined by the simulation, the molecular structure could be predicted by using the another simulation technique. The information on the number of branches and the methylene linkage sequence in copolymer were obtained. The molecule obtained from the molar ratio of $\mathrm{P}$ to $\mathrm{BP}=3 / 1$ in the feed had branches about twice as many as that of the molecule obtained from the $\mathrm{P} / \mathrm{BP}=1 / 3$, and the long sequence of $o, o^{\prime}$-methylene linkage was found in the copolymer obtained from the high content of $\mathrm{BP}$ in the feed.
\end{abstract}

KEY WORDS Co-condensation / Formation Reaction / Phenol / p-tert-Butylphenol / Computer Simulation / Monomer Reactivity Ratio / Copolymer Composition / Monomer Composition / Number of Branches / Methylene Linkage Sequence /

Phenolic polymer has some characteristics such as heat resistance, dimensional stability, and insulation, which are very important for industrial materials. Many researchers have reported on its preparation and its applications. Since the formation reaction is very complex because the reaction consists of addition and condensation and the gelation easily occurs due to the trifunctionality of phenol, however, it is difficult to analyze the formation mechanism kinetically and statistically, and also to determine the molecular structure. In order to analyze this complex reaction mechanism, we have proposed a Monte Carlo (MC) computer simulation technique. ${ }^{1-6}$ This simulation was applied to the initial stages of the formation of phenolic polymers and the gelation, and the information about the ratio of reaction rate of addition to condensation, the reactivity ratio of the ortho position to the para in phenolic nucleus, and also about the molecular structures such as the number of branches and the molar fraction of $o, o^{\prime}-$, $o, p^{\prime}-$, and $p, p^{\prime}$-methylene linkage were obtained.

Recently, a co-condensation of two kinds of phenols is tried to give high-performance properties to phenolic polymer as an engineering material. We obtained the phenolic co-condensed polymer with various compositions and different structures, depending on the molar ratio in the feed and the reactivities of monomers. ${ }^{7}$ Compared with radical and ion copolymerization reactions, however, co-condensation reactions have been scarcely studied except for a few studies reported by Korshak et al. ${ }^{8}$ and Aoki. ${ }^{9}$ In previous paper, we applied the MC simulation technique to the simple cocondensation reaction of $p$-cresol/p-tert-butylphenol/ formaldehyde and $o, o^{\prime}$-bishydroxymethyl-p-cresol $/ o, o^{\prime}-$ bishydroxymethyl-p-tert-butylphenol systems and the information about the relative reactivity ratio of monomer and the composition of copolymer. ${ }^{10}$ In this paper, the mechanism of the complex co-condensation of phenol and p-tert-butylphenol with formaldehyde is analyzed by means of the simulation technique, and the relative reactivity ratio of phenol to $p$-tert-butylphenol is determined and then the effect on the molecular structure of co-condensed polymer is discussed.

\section{EXPERIMENTAL}

\section{Materials}

Commercially available phenol was distilled and then used. p-tert-Butylphenol was used without further purification. Acid in formalin was removed by passing through a column packed with anion-exchange resins (Amberlite XE 168) and then the concentration of formaldehyde was determined by sodium sulfite method. Commercially available hydrochloric acid was used as a catalyst. Acetone was distilled and then used for the fractionation of co-condensed polymer, and for measurements of vapor pressure osmometry (VPO) it was distilled after refluxing over potassium permanganate. Tetrahydrofuran (THF) was distilled and then used for measurements of gel permeation chromatography (GPC).

\section{Preparation of Copolymer}

Phenol $/ p$-tert-butylphenol co-condensed polymer was prepared as follows. Phenol, p-tert-butylphenol, formalin, and hydrochloric acid as a catalyst were charged in a three-necked flask equipped with a reflux condenser and a stirrer. The mixture was heated at $65^{\circ} \mathrm{C}$ for $3 \mathrm{~h}$. The reaction condition for the preparation of samples was summarized in Table I.

\section{Fractionation of Copolymer}

Samples A to $\mathrm{G}$ were fractionated by successive solution fractionation method with acetone as a solvent and water as a nonsolvent. The fraction was used to determine the composition and the structure of copolymer. 


\section{Measurements}

GPC analysis was carried out by a JASCO HPLC FLC-A700 or a Shimadzu HPLC LC-6A equipped with $50-\mathrm{cm}$ polystyrene gel packed columns (Shodex A802+ $\mathrm{A} 802, \mathrm{~A} 803+\mathrm{A} 803$, and TOSOH TSKgel G3000H8+ $\mathrm{G} 2000 \mathrm{H} 8+\mathrm{G} 2000 \mathrm{H} 8+\mathrm{G} 2000 \mathrm{H} 8$ ) and a JASCO UVIDEC 100 (wave length 270nm) and a Mitsumi RI monitor SF-1107 as detectors. THF was used for the mobile phase. The flow rate was $1.0 \mathrm{~mL} \mathrm{~min}^{-1}$ for Shodex columns, and $1.5 \mathrm{~mL} \mathrm{~min}^{-1}$ for TSKgel columns. The concentration of the sample in THF were $0.3 \mathrm{wt} \%$ for $\mathrm{UV}$ detector, and $3 \mathrm{wt} \%$ or $5 \mathrm{wt} \%$ for the RI . The molecular weight of each fraction was determined by VPO measurements using a Hitachi Perkin-Elmer Model 115 or a Corona Model 117 molecular weight apparatus. Acetone was used as a solvent and the calibration curve was obtained by the use of benzyl-acetone solution. ${ }^{1} \mathrm{H}$ NMR spectra were obtained with a JEOL JNM-FX100 spectrometer $\left(100 \mathrm{MH}_{\mathrm{Z}}\right)$. Deuterochloroform and pentadeuteropyridine were used as a solvent and tetramethylsilane (TMS) was used as a reference.

Table I. Reaction conditions for preparation of phenolic co-condensed polymer

\begin{tabular}{|c|c|c|c|c|c|}
\hline \multirow{2}{*}{$\begin{array}{l}\text { Sample } \\
\text { code }\end{array}$} & \multicolumn{4}{|c|}{ Molar ratio } & \multirow{2}{*}{$\begin{array}{c}\text { Temperature } \\
{ }^{\circ} \mathrm{C}\end{array}$} \\
\hline & $\mathrm{P}$ & $\mathrm{BP}$ & $\mathrm{F}$ & HCL & \\
\hline A & 3 & 1 & 4 & 0.20 & 65 \\
\hline B & 2 & 1 & 3 & 0.15 & 65 \\
\hline $\mathrm{C}$ & 3 & 2 & 5 & 0.25 & 65 \\
\hline $\mathrm{D}$ & 1 & 1 & 2 & 0.10 & 65 \\
\hline $\mathrm{E}$ & 2 & 3 & 5 & 0.25 & 65 \\
\hline $\mathrm{F}$ & 1 & 2 & 3 & 0.15 & 65 \\
\hline G & 1 & 3 & 4 & 0.20 & 65 \\
\hline
\end{tabular}

a P, phenol; BP, p-tert-butylphenol; F, formaldehyde.

\section{COMPUTER SIMULATION TECHNIQUE}

In advance, the actual reaction have been performed and the extent of reaction $(p)$ and the molecular weight distribution (MWD) have been obtained from the GPC chromatogram. The extent of reaction is defined as

$$
p=\left(N_{0}-N\right) / N_{0}
$$

where $N_{0}$ and $N$ are the number of molecules before reaction and that at the prescribed time.

In this computer simulation, the following assumptions are used:

1) The reactivity of functional group in copolymer is independent of the chain length.

However, the reactivity of monomer is distinguished from other species.

2) Intramolecular reaction does not occur.

3) Dimethylene ether linkage is not formed.

At first, the starting molecules and functional groups shown in Scheme 1 are stored in the storage of computer. From these functional groups, one of formaldehyde (F) or hydroxymethyl group (M) is selected and then one of phenolic nuclear hydrogen $(\mathrm{H})$ is chosen to react with $\mathrm{F}$ or $\mathrm{M}$. If $\mathrm{F}$ is selected, the addition reaction hypothetically occurs in the computer. In contrast, if $\mathrm{M}$ is selected, the condensation occurs hypothetically. The molecule newly formed is fed back into the storage of computer. Repeating this procedure, the number of molecules decreases and the MWD of the hypothetical product changes progressively in the computer. This is repeated until the extent of reaction reaches the same value as that of the prepared copolymer obtained by GPC measurements in advance. The reaction is simulated freely by inputting various selecting probabilities. In the simulation, the probability that a functional group will be selected in the computer is assumed to be proportional

HCHO (F)<smiles>Oc1ccc([18OH])cc1</smiles>

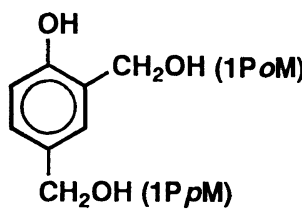
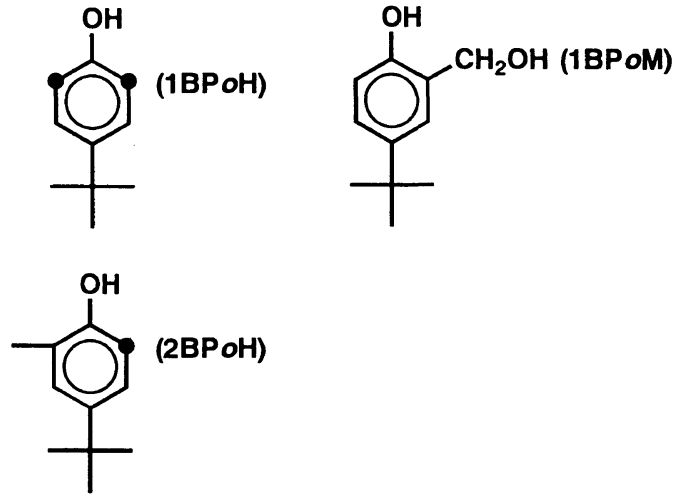

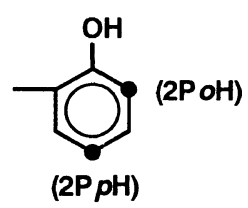

$$
\begin{aligned}
& \text { F : formaldehyde } \\
& \text { P : phenol } \\
& \text { BP : p-tert-butylphenol } \\
& \text { H : nuclear hydrogen } \\
& \text { M : hydroxymethyl group }
\end{aligned}
$$

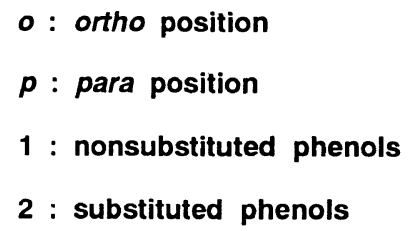

Scheme 1. Molecular species and functional groups. 


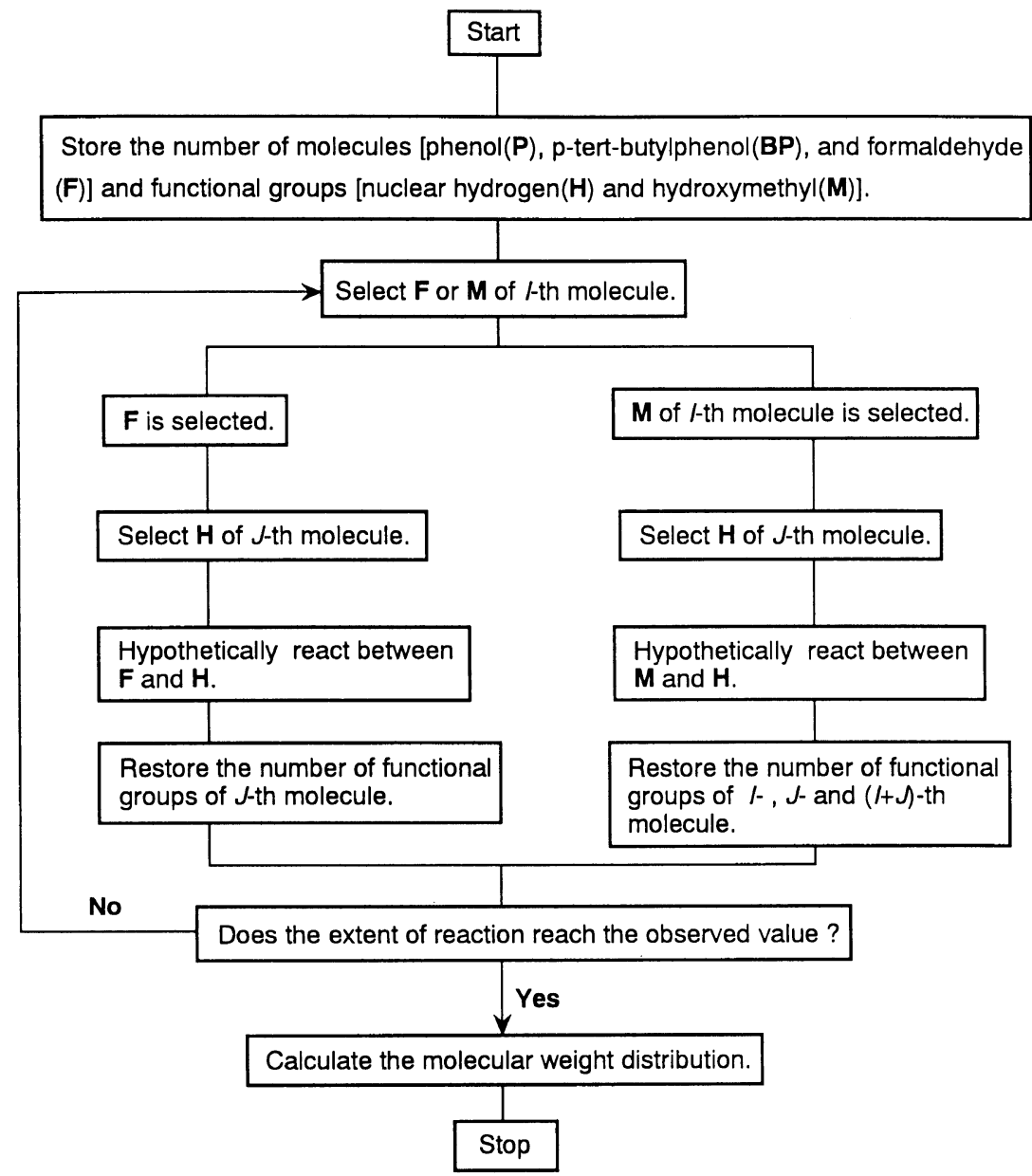

Figure 1. The simulation flow chart for phenol/p-tert-butylphenol co-condensation system.

to its reactivity in the reaction. The selecting probability that gives the same MWD as that of the prepared copolymer is the most reasonable of all. The flow chart of this simulation is illustrated in Figure 1.

The following reactivity ratios are used to simulate the co-condensation:

$$
\begin{aligned}
& W=I(\mathrm{P} o \mathrm{M}) / I(\mathrm{~F}) \\
& X=I(\mathrm{BP} o \mathrm{H}) / I(\mathrm{P} o \mathrm{H})=I(\mathrm{BP} o \mathrm{M}) / I(\mathrm{P} o \mathrm{M}) \\
& Y=I(\mathrm{P} p \mathrm{H}) / I(\mathrm{P} o \mathrm{H})=I(\mathrm{P} p \mathrm{M}) / I(\mathrm{P} o \mathrm{M}) \\
& Z=I(2 \mathrm{H}) / I(1 \mathrm{H})
\end{aligned}
$$

where $I(f)$ represents the probability that the functional group, $f$, will be selected. $o$ and $p$ represent the ortho and para position of phenolic nucleus, respectively. Therefore, for example, $I(\mathrm{BP} o \mathrm{H})$ shows the selecting probability of the nuclear hydrogen at the ortho position of $p$-tert-butylphenol. $1 \mathrm{H}$ and $2 \mathrm{H}$ represent the nuclear hydrogen of phenol monomer and that of substituted phenols, respectively. $W$ is the ratio of reaction rate of condensation to addition, $X$ is the reactivity ratio of p-tert-butylphenol to phenol, $Y$ is the reactivity ratio of the para position to the ortho in phenolic nucleus, and $Z$ is the reactivity ratio of substituted phenols to phenol monomer.

On the other hand, another simulation was run to obtain the information about the molecular structure of copolymer. From the molecule formed hypothetically in the simulation using the most reasonable values of parameters $X$ and $Y$, the data for the molar fraction and the sequence of $o, o^{\prime}-, o, p^{\prime}$-, and $p, p^{\prime}$-methylene linkage, and the number of branches in the copolymer can be obtained.

\section{RESULTS}

Molecular Weight Distribution (MWD)

The MWD of the prepared co-condensed phenolic polymer was determined by GPC measurements. The typical chromatogram and the assignment of the peaks, determined by using commercial standard samples, were shown in Figure 2. It was so difficult to assign the peaks beyond No.5, due to the overlapping of several kinds of species, that these peaks were gathered as the peak of No.6. The weight fraction of each peak was determined as an observed value and the result was compared with that obtained from the MC simulation. The comparison of MWD was done and summarized in Table II for the reaction of sample $B$. In this table, the simulation result was obtained from the values of parameters, $W=15.0$, $X=1.9, \quad Y=2.9$, and $Z=0.9$ and the MWD of the simulation was in excellent agreement with that of the observed.

\section{Molecular Structure}

The molecular structure of the copolymer was determined with ${ }^{1} \mathrm{H}$ NMR spectra. The typical spectra 

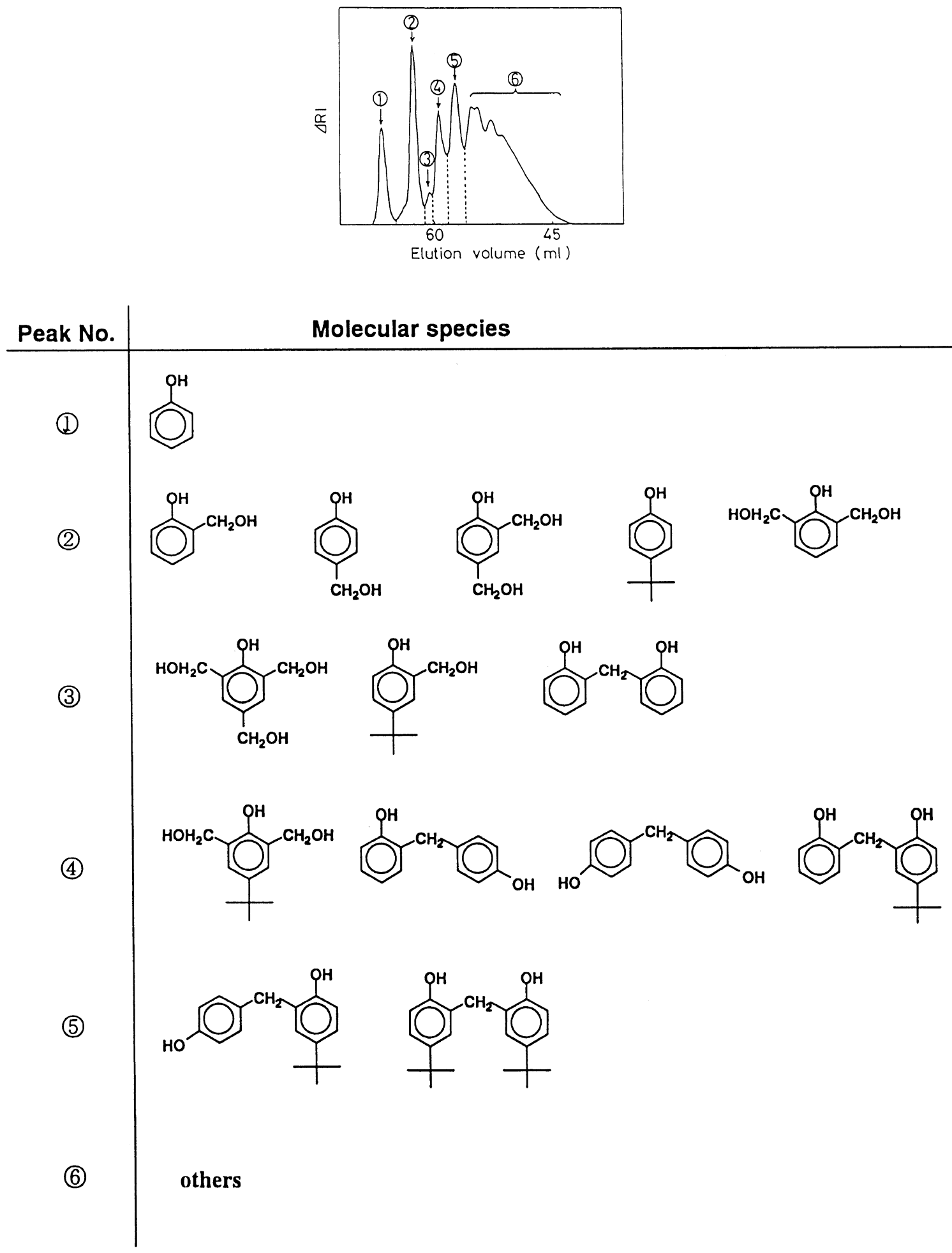

Figure 2. The GPC chromatogram and the assignment of phenol $/ p$-tert-butylphenol co-condensed polymer.

of sample $\mathrm{F}$ were shown in Figure 3. In deuterochloroform, the peaks of $1.26 \mathrm{ppm}$ and $3.80 \mathrm{ppm}$ have been assigned to be methyl proton signals of tert-butyl group and methylene proton signals of methylene linkage between phenolic units. In pentadeuteropyridine, the values of chemical shifts of $o, o^{\prime}-, o, p^{\prime}-$, and $p, p^{\prime}$-methylene linkages were given to be $4.50,4.23$, and $3.86 \mathrm{ppm}$, respectively. ${ }^{11}$ The molar fraction of each methylene linkage and the content of BP in co-condensed polymer were obtained from the ratio of their intensities in the spectra.
The effect of monomer compositions in the feed on the composition of the co-condensed polymer of $M_{n}=$ about 1000 was shown in Figure 4 . The simulation result was also shown in the figure. The dashed line in the figure indicated the composition of the copolymer obtained by the ideal copolymerization. Obviously, the observed composition of the co-condensed polymer was near those of the ideal copolymer and the deviation between the observed result and the simulation was found. To consider the reason of the deviation, the molecular weight dependence of composition of the 

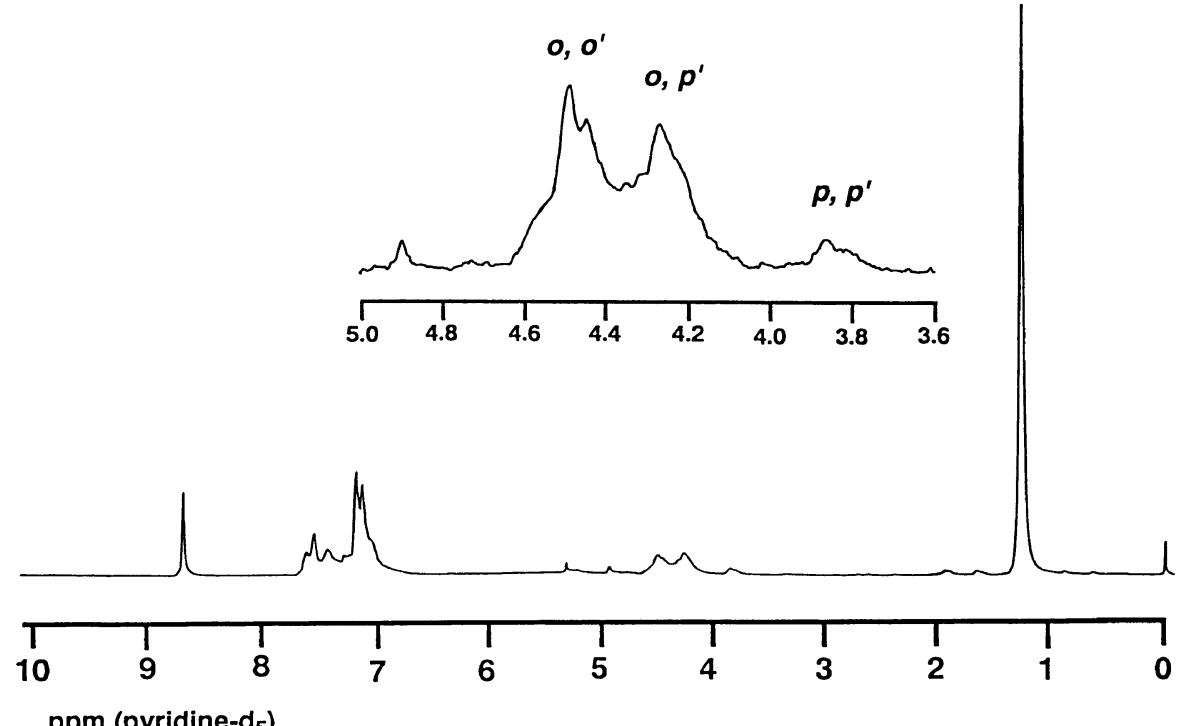

Figure 3. ${ }^{1} \mathrm{H}$ NMR spectra of phenol/p-tert-butylphenol co-condensed polymer (sample F) in pentadeuteropyridine.

Table II. Comparison of the MWD between the observed results and the simulation ${ }^{\mathrm{a}}$

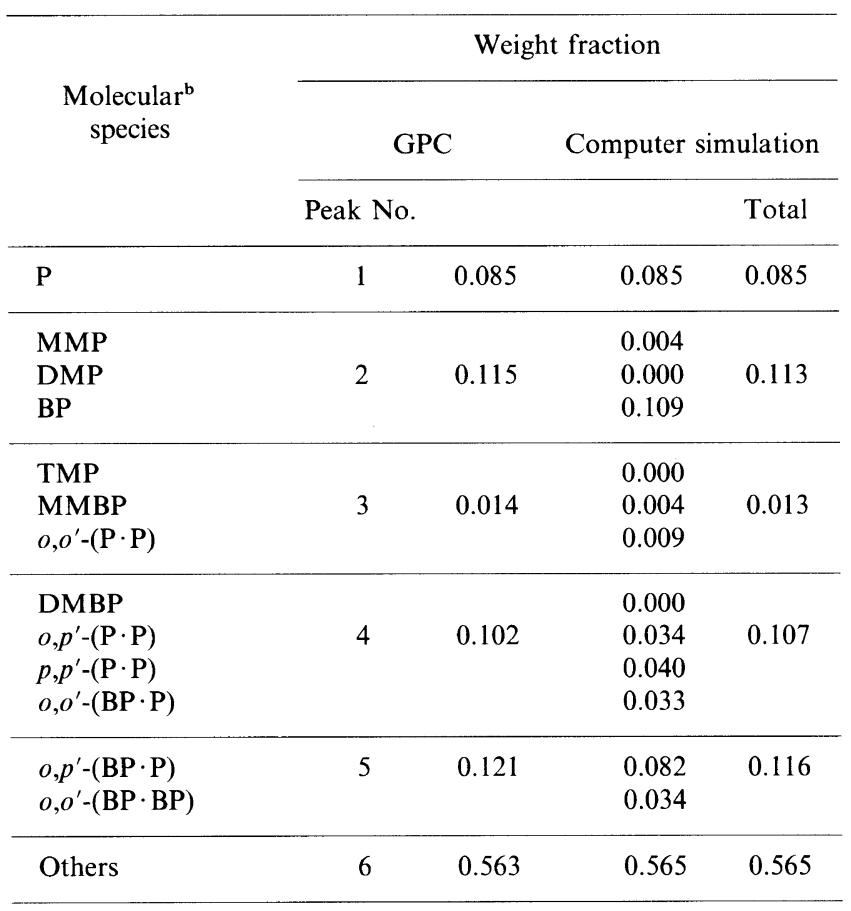

${ }^{a}$ Reaction condition: $\mathrm{P} / \mathrm{BP} / \mathrm{F} / \mathrm{HCl}=2 / 1 / 3 / 0.15$; temperature, $65^{\circ} \mathrm{C}$; time, $40 \mathrm{~min}$. Simulation parameters: $W=15.0, \quad X=1.9 ; \quad Y=2.9$; $Z=0.9$. ${ }^{\mathrm{b}}$ Abbreviations: $\mathrm{P}$, phenol; BP, 4-tert-butylphenol; MMP, 2- or 4-hydroxymethylphenol; DMP, 2,4- or 2,6-bishydroxymethylphenol; TMP, 2,4,6-trishydroxymethylphenol; MMBP, 2-hydroxymethyl4-tert-butylphenol; DMBP, 2,6-bishydroxymethyl-4-tert-butylphenol; $o, o^{\prime}$-(P·P), 2,2'-dihydroxydiphenylmethane; $p, p^{\prime}$-(P·P), 2,4'-dihydroxydiphenylmethane; $p, p^{\prime}-(\mathrm{P} \cdot \mathrm{P}), 4,4^{\prime}$-dihydroxydiphenylmethane; $o, o^{\prime}$ (BP·P), 2,2'-dihydroxy-5-tert-butyldiphenylmethane; $o, p^{\prime}$-(BP·P), 2,4'dihydroxy-5-tert-butyldiphenylmethane; $o, o^{\prime}$-(BP-BP), 2,2'-dihydroxy5,5'-di-tert-butyldiphenylmethane.

co-condensed polymer was determined by using the fraction with different composition and the result was shown in Figure 5. The co-condensed polymer composition was found to be strongly affected by the molecular weight.

On the other hand, the effect of monomer compositions in the feed on the molar fraction of each methyl-

Polym. J., Vol. 28, No. 9, 1996

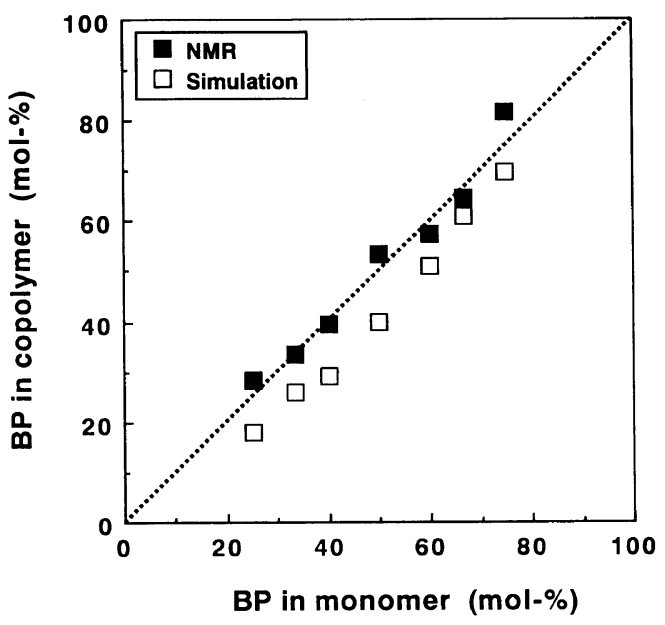

Figure 4. Plot of the composition of phenol/p-tert-butylphenol cocondensed polymer against monomer composition in the feed. The molecular weight $\left(M_{n}\right)$ of copolymer is about 1000 .

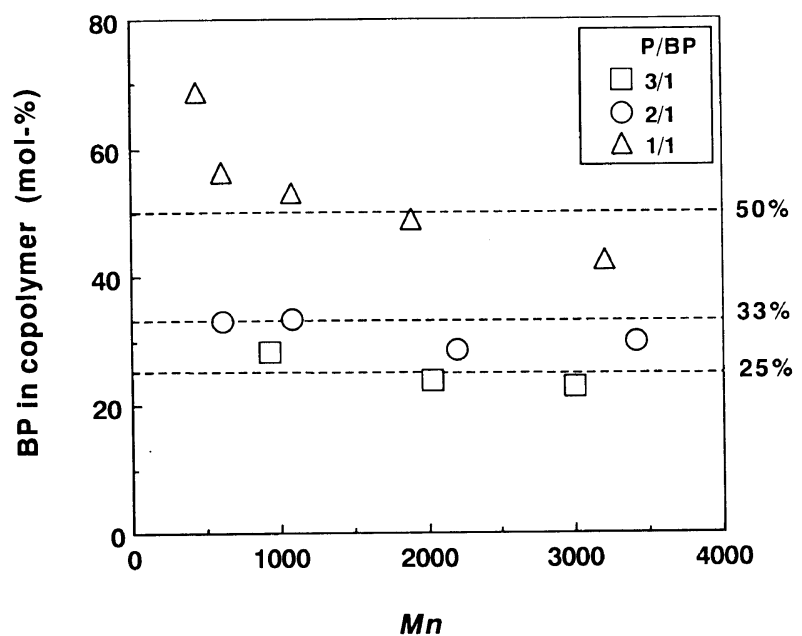

Figure 5. Plots of the composition of phenol/p-tert-butylphenol co-condensed polymer obtained from the molar ratios of phenol to $p$-tert-butylphenol in the feed, $1 / 1,2 / 1$, and $3 / 1$ against molecular weight.

ene linkage $\left(o, o^{\prime}, o, p^{\prime}\right.$, and $\left.p, p^{\prime}\right)$ in the co-condensed polymer was shown in Figure 6 . In this figure, the symbol and the solid line represent the results of ${ }^{1} \mathrm{H}$ NMR 


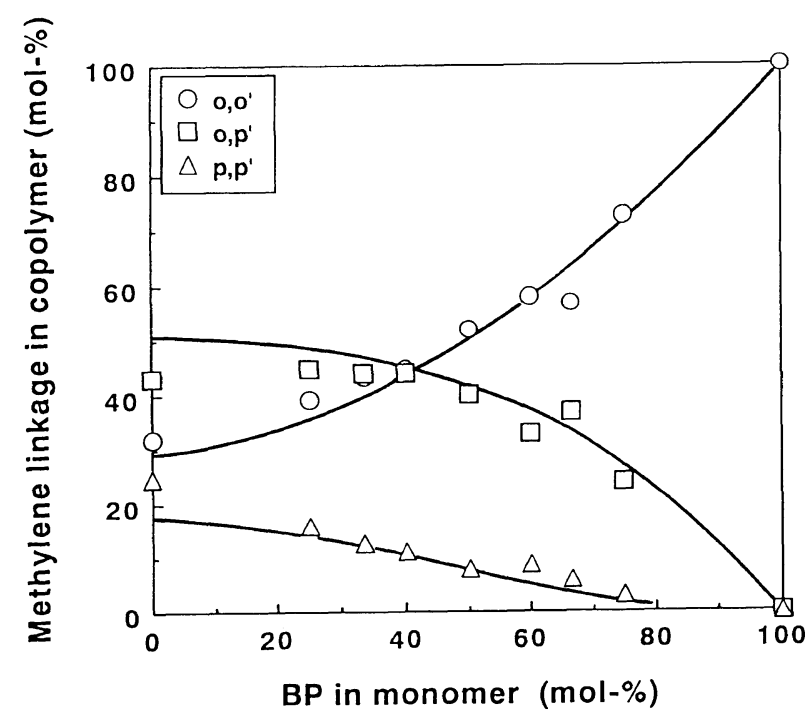

Figure 6. Plots of the molar fraction of $o, o^{\prime}-, o, p^{\prime}-$, and $p, p^{\prime}$-methylene linkage in phenol/p-tert-butylphenol co-condensed polymer against monomer composition in the feed.<smiles>Oc1ccccc1</smiles>

(3)<smiles>CC(C)(C)c1ccc(O)cc1</smiles><smiles>Cc1cccc(O[AsH3])c1Cc1cc(C(C)(C)C)cc([13CH3])c1O</smiles>

НСно (1)<smiles>O=COCc1cc(CO)ccc1O</smiles>

Scheme 2. Relative reactivity of functional groups.

measurements and the simulation, respectively. The result obtained from the simulation was in good agreement with the observed.

\section{Formation of Co-condensed Polymer}

The MC computer simulation for the phenolic cocondensation was done and controlled by the extent of reaction, $p$, which was calculated from the consumption of phenol monomer in this study. The most suitable values of $W, X, Y$, and $Z$ were obtained to give the same molecular weight distribution in the simulation as that of the prepared copolymer. The parameter value was independent of the reaction condition and the extent of reaction, and the most reasonable values of the simulation parameters were determined to be $W=12$ $15, X=2, Y=3$, and $Z=0.8-0.9$. From these results, the relative reactivities of functional groups and molecules were obtained and summarized in Scheme 2.

The structural analysis of the co-condensed polymer was also carried out with the another MC simulation based on the reactivities of phenol (P) and p-tertbutylphenol (BP). From this simulation using the parameters $X$ and $Y$, a molecular structure can be easily predicted by inputting the composition of monomer in the feed and the degree of polymerization. The result was obtained to form a co-condensed polymer hypothetically in the computer, as shown in Figure 7. The figure showed the most probable structure consisting of

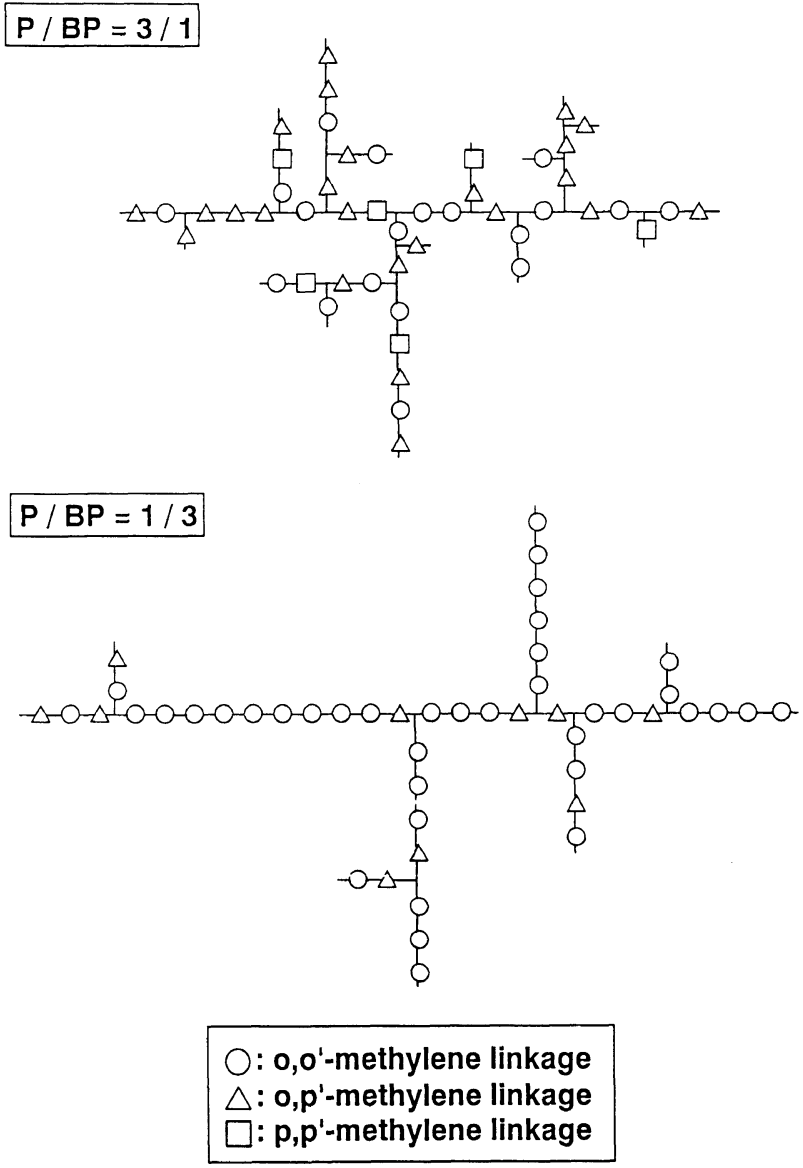

Figure 7. The molecular structures consisting of 50 phenolic units of phenol $/ p$-tert-butylphenol co-condensed polymer obtained from the molar ratios of phenol to $p$-tert-butylphenol in the feed, $3 / 1$ and $1 / 3$. The most reasonable values of parameters $X=2$ and $Y=3$ are used to run the simulation.

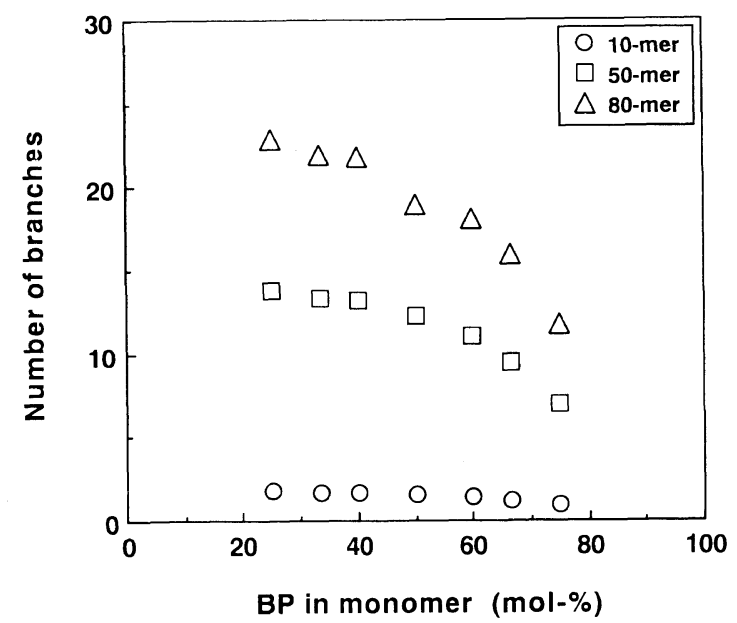

Figure 8. Plots of the number of branches in phenol $/ p$-tert-butylphenol co-condensed polymer consisting of 10,50 , and 80 phenolic units against monomer composition in the feed.

50 phenolic units for samples $\mathrm{A}(\mathrm{P} / \mathrm{BP}=3 / 1$ in the feed) and $\mathrm{G}(\mathrm{P} / \mathrm{BP}=1 / 3)$. The molecular structure changed by the molar ratio of $\mathrm{P}$ to $\mathrm{BP}$ in the feed. For phenolic polymers, one of the most important structural properties is the degree of branch in polymer. The relationship between the number of branches and the composition of monomer in the feed was shown in Figure 8. The number of branches changed by the monomer 
composition and the degree of polymerization in the copolymer.

\section{DISCUSSION AND CONCLUSION}

\section{Molecular weight Distribution (MWD)}

The run of this simulation was based on the extent of reaction calculated from the MWD of the prepared co-condensed polymer. Thus, it is important to inform the MWD exactly. The MWD of the prepared copolymer was analyzed in detail by using GPC measurements with the calibration of the standard samples. The accuracy of the simulation result was shown by little difference in the MWD between the simulation and the observed (see Table II). This indicates that the MC simulation technique is valid for the analysis of the formation of the phenolic co-condensed polymer. In addition, the more detailed information about the MWD, which can not be determined by GPC analysis, can be made clear from the simulation results.

\section{Molecular Structure}

In copolymerization, it is well known that the composition of monomer in the feed and the reactivity of monomer affect the composition of copolymer. The relationship between the composition of copolymer and the composition of monomer in the feed is well investigated for radical and ion copolymerizations. However, the relation for co-condensations has not been reported in detail. One of our aims is to make the relationship clear by means of the MC simulation technique based on the reactivity of monomer. The observed composition of the co-condensed polymer for $\mathrm{P} / \mathrm{BP}$ system appears to follow that of the ideal copolymerization, but the simulation result of the copolymer composition was not so in good agreement with the observed in spite of the excellent agreement in the MWD (see Figure 4). To make the reason for the deviation clear, the molecular weight dependence of composition of the cocondensed polymer was examined. Obviously, the composition was dependent on the molecular weight and this trend was stronger on using the higher content of BP in the feed (see Figure 5). The content of BP in copolymer was higher as the molecular weight was lower. The molecular weight dependence of the copolymer composition seems to be attributed to the difference in the reactivity of the copolymer, depending on the copolymer composition. The details of the discussion about the relation between the copolymer composition and the reactivity of the copolymer are given in the next section.

On the other hand, the molar fraction of each methylene linkage changed smoothly according to the monomer composition and the results of ${ }^{1} \mathrm{H}$ NMR measurements and the simulation were in agreement each other (see Figure 6).

From these results, it was concluded that the cocondensed polymer composition as well as the structure can be controlled by the monomer composition in the feed.

\section{Formation of Co-condensed Polymer}

From the relative reactivities summarized in Scheme 2 , the following conclusions were derived for phenol
(P)/p-tert-butylphenol (BP) co-condensation system.

1) The rate of condensation reaction was about 10 times faster than that of the addition.

2) The reactivity ratio of para position of phenol was about 3 times higher than that of the ortho.

3) The reactivity of the functional group at ortho position of BP was about twice higher than that of $\mathrm{P}$. Thus, the reactivity ratio of $\mathrm{P}$ to $\mathrm{BP}$ was determined to be $5 / 4$.

4) The substitution on phenolic nucleus lowered the reactivity of phenols slightly.

The results described in 1) and 2) agreed with those for the phenol-formaldehyde system reported previous$\mathrm{ly}^{2}$ The higher reactivity of the para position was confirmed by the comparison of the GPC chromatogram of the reaction product obtained from $o, p$-dimethylphenol and formaldehyde with that obtained from $o, o^{\prime}$ dimethylphenol and formaldehyde.

Based on the relative reactivities obtained above, the molecular structure of the co-condensed phenolic polymer can be predicted with the computer. As shown in Figure 7, the structure changed with the variation of the monomer composition in the feed. From this simulation technique, the number of branches can be counted, which is unable to be determined directly. The number of branches was dependent on the monomer composition. Especially, it was strongly influenced by the BP content in the range of $40-80 \%$ (see Figure 8 ). From the figure, it became clear that the number of branches becomes larger as the proportion of phenol in the copolymer increases. For example, the molecule of sample $\mathrm{A}(\mathrm{P} / \mathrm{BA}=3 / 1)$ had branches about twice as many as that of sample $\mathrm{G}(\mathrm{P} / \mathrm{BP}=1 / 3)$.

As can be seen from the molecular structure, the distribution of methylene linkage sequence of sample A was different from that of sample $\mathrm{G}$. The long sequence of $o, o^{\prime}$-methylene linkage was found in the copolymer obtained from the higher content of BP in the feed (see Figure 7). The reason was not clear in this study. However, it should be related to that intramolecular hydrogen bonds can be formed easily between hydroxyl groups of neighbor phenolic units linked by $o, o^{\prime}-$ methylene linkage.

As already described, the composition of the phenolic copolymer was dependent on the molecular weight. According to GPC chromatograms of copolymers of $\mathbf{P} / \mathbf{B P}$ system, it became obvious that the higher molecular weight component could not be formed, if the larger amount of BP was fed. We concluded that the high content of BP in the copolymer molecule must make the reactivity of the molecule lower, leading to the molecular weight smaller. The lower reactivity of the copolymer with higher content of BP can be attributed to the shielding effect described by Imoto et al., that is, the rate constant of the formation of larger molecules than 5-mer falls to about half of that of smaller molecules in the reaction of $p$-methylphenol with formaldehyde. ${ }^{12}$ This is because that the conformation of the larger molecule is a compact sphere owing to the intramolecular hydrogen bond between phenolic hydroxyl groups and some reactive sites are hidden and shielded in the sphere to be impossible to react. We concluded that in the case that a larger amount of BP was contained in the copoly- 
mer, the molecular conformation was more compact by intramolecular hydrogen bonds, which are formed among hydroxyl groups of phenolic units linked by $o, o^{\prime}$-methylene linkage, and the reactivity became lower. This means that the reactivity of the functional group in the copolymer is dependent on the copolymer composition. In other words, the reactivity of the functional group changes with the molecular weight. In this simulation, however, the molecular weight dependence of the copolymer composition could not be found. Because the reactivity of the functional group in the simulation unchanges with increasing the molecular weight as described in the assumption (see "Computer Simulation Technique"). This unsuitable assumption must cause the deviation between the observed result and the simulation in Figure 7.

In conclusion, we were able to prepare phenol $/ p$-tertbutylphenol co-condensed polymers and obtain the information about the formation mechanism and the molecular structure by the MC simulation technique. The relative reactivities of the functional groups and the monomer were determined. From these results, the molecular structure could be also predicted by using the another simulation. This technique must be useful for the molecular design of new copolymer system. Even though simple assumptions were used in this simulation, the reasonable results were obtained. If the copolymer composition dependence or the molecular weight dependence of the reactivity of functional group will be considered in the simulation, the more details of the information about the formation mechanism and the molecular structure of co-condensed phenolic polymers will be able to be obtained.

Acknowledgments. The authors wish to thank Ms. K. Kawai for her technical assistance.

\section{REFERENCES}

1. S. Ishida, J. Matsui, S. Ozawa, and K. Kaneko, Kobunshi Ronbunshu, 34, 167 (1977).

2. S. Ishida, M. Murase, and K. Kaneko, Polym. J., 11, 835 (1979).

3. S. Ishida, Netsu Kokasei Jushi, 1, 40 (1980).

4. S. Ishida, Y. Tsutsumi, and K. Kaneko, J. Polym. Sci., Polym. Chem. Ed., 19, 1609 (1981).

5. S. Ishida, S. Wakaki, Y. Kato, and Y. Nakamoto, Ind. Eng. Chem., Prod. Res. Div., 23, 380 (1984).

6. S. Ishida, T. Yamagishi, and Y. Nakamoto, Preprints of Japan-US Polymer Symposium, The Society of Polymer Science, Japan, Tokyo, 1985.

7. H. Sue, E. Ueno, Y. Nakamoto, and S. Ishida, J. Appl. Polym. Sci., 38, 1305 (1989).

8. V. V. Korshak, S. V. Vinogradova, V. A. Vasnev, Yu. I. Perfilov, and P. O. Okulevich, J. Polym. Sci., 11, 2209 (1973).

9. (a) A. Aoki, Kobunshi Ronbunshu, 51, 420 (1994); (b) A. Aoki, Kobunshi Ronbunshu, 51, 428 (1994).

10. T. Yamagishi, K. Sakuda, M. Minami, Y. Nakamoto, and S. Ishida, Kobunshi Ronbunshu, 51, 394 (1994).

11. T. Yoshikawa and J. Kumanotani, Makromol. Chem., 131, 273 (1970).

12. M. Imoto, I. Ijichi, C. Tanaka, and M. Kinoshita, Makromol. Chem., 113, 117 (1968). 